\title{
HBV and HCV infection in Japanese dental care workers
}

\author{
YUMIKO NAGAO, HISAKO MATSUOKA, TAKUMI KAWAGUCHI, TATSUYA IDE and MICHIO SATA \\ Department of Digestive Disease Information and Research, Kurume University School of Medicine, Kurume, Japan
}

Received February 4, 2008; Accepted March 19, 2008

\begin{abstract}
Protective measures against occupational exposure to the hepatitis B virus (HBV) and hepatitis $\mathrm{C}$ virus (HCV) must be taken in order to prevent infection in dental care workers. To determine the best way to protect these workers, our study examined viral hepatitis infection in dental care workers in regions with a high prevalence of $\mathrm{HCV}$ infections in Japan. In total, 141 dental care workers (including dentists, dental hygienists and dental assistants) were enrolled. After a questionnaire to elicit demographic information was administered by an oral surgeon, hepatitis B surface antigen (HBsAg), antibody to HBs (anti-HBs), antibody to hepatitis B core antigen (anti-HBc) and antibody to HCV (anti-HCV) were measured. When necessary, $\mathrm{HBeAg}$, anti-HBe, levels of HBV DNA, anti-HBc IgM and HCV RNA in serum were measured. Of the dental care workers included, 68 (48.2\%) had been immunized with a HBV vaccine. Only 9 wore a new pair of gloves for each new patient being treated, 36 changed to a new pair only after the old gloves were torn and 24 did not wear any gloves at all. No one was positive for HBsAg or anti-HCV, though $73(51.8 \%)$ and 17 (12.1\%) workers were respectively positive for anti-HBs and anti-HBc. The positive rate of anti-HBc varied directly with worker age and experience. Of the 68 workers immunized with HBV vaccine, $51(75 \%)$ were positive for anti-HBs. Of the 63 workers who were not so immunized, 17 (27\%) were positive for anti-HBs and 15 of these were also positive for anti-HBc. Immunized workers were more protected against HBV infection than non-immunized workers, indicating that $\mathrm{HBV}$ vaccine was a useful measure for protection against the infection. The anti-HBc positive rate was significantly higher among dental care workers than general blood donors, suggesting that frequency of exposure to HBV was greater in
\end{abstract}

Correspondence to: Dr Yumiko Nagao, Department of Digestive Disease Information and Research, Kurume University School of Medicine, 67 Asahi-machi, Kurume 830-0011, Japan

E-mail:nagao@med.kurume-u.ac.jp

Abbreviations: $\mathrm{HBV}$, hepatitis B virus; HBsAg, hepatitis B surface antigen; anti-HBs, antibody to $\mathrm{HBsAg}$; anti-HBc, antibody to hepatitis $\mathrm{B}$ core antigen; $\mathrm{HCV}$, hepatitis $\mathrm{C}$ virus; anti-HCV, anti-bodies to HCV; HCC, hepatocellular carcinoma; CLEIA, chemiluminescent enzyme immunoassay

Key words: dentists, hepatitis B virus, hepatitis C virus, vaccine dental care workers. HBV vaccination should be made compulsory for all dental care workers who handle sharp instruments.

\section{Introduction}

It is important to protect dental care workers (who perform invasive procedures daily) from nosocomial, blood-transmissible infections of the hepatitis B virus (HBV) and hepatitis $\mathrm{C}$ virus $(\mathrm{HCV})$. There are $\sim 1.5$ million persistent HBV carriers and 2 million persistent HCV carriers in Japan. These carriers may develop hepatocellular carcinoma (HCC) decades later. The incidence of HCC continues to increase in Japan and $\sim 80$ and $10 \%$ of HCC are due to HCV and HBV, respectively (1). Treatment methods for hepatitis $\mathrm{C}$ and hepatitis $\mathrm{B}$ are now well established, continue to improve annually and their effects are dramatic.

The worldwide HBV infection rate is higher in dentists than in the general population: 6 times higher in the USA, 4 times higher in Germany and 2.5 times higher in Japan. The incidence of HBV infection among dentists is $10.8 \%$ in Brazil (2), $9 \%$ in the USA (3) and 7\% in Germany (4). Among medical care workers, dentists have the highest incidence of HBV infection and this incidence increases with the length of clinical experience of the dentist $(5,6)$. An investigation conducted in 1978 in Japan found approximately half of dentists with 5 or more years of clinical experience were infected with HBV or had a history of HBV infection (7). A study of 998 dentists conducted in 17 regions throughout Japan from 1978 to 1982 reported that 37 (3.7\%) were hepatitis B surface antigen (HBsAg)-positive and 420 (42.1\%) were antibody to HBs (anti-HBs)-positive (8). The results indicated that infection occurred at work without the dentists' knowledge. Thus dental care workers should be advised to receive a hepatitis $\mathrm{B}$ vaccine and it should be confirmed if they have acquired immunity to HBV.

What is the HCV infection rate in dentists in Japan? The anti-HCV-positive rate was $2.6 \%$ (10/382) according to the seroepidemiological survey of Shinozaki et al who used frozenpreserved serum obtained from dentists between 1986 and 1994 (9). However, the status of HCV infection was unclear, as the mean age of subject dentists and other information were not recorded. In New York city, the positive rate of antiHCV was clearly higher among oral surgeons (9.3\%) and other dentists $(1.75 \%)$ than blood donors $(0.14 \%)$ (10). The finding shows that morbidity in dentists differs by specialties.

In recent years, the infection rate in dentists in Japan remains unclear. The last estimates were made in the 1980s and 
1990s, before more sensitive tests became available. Viral levels have never been measured (7-9). The status of hepatitis viral infection in dental care workers in the northern part of Kyushu, where the infection rates are the highest in Japan should be determined in order to assess the extent to which further health measures are needed to protect and maintain the health of dental care workers.

The present study screened for the presence of HBV and $\mathrm{HCV}$ infections in dental care workers in the Fukuoka prefecture (northern Kyushu). Since viral hepatitis is treatable, this investigation could contribute to the health maintenance of dental care workers.

\section{Patients and methods}

Patients. Participants included 141 dentists belonging to the $\mathrm{X}$ Dental Association in the Fukuoka prefecture and dental care workers (dental hygienists, assistants, mechanics and clerks) employed at dental clinics. Each member was notified by mail about the study before the examination. The examination was performed on 2 days (September 22 and 27, 2007).

Methods. Each participant gave informed consent and had a blood sample taken. An oral surgery specialist interviewed the subjects. Items of inquiry included gender, age, occupation, years employed as a dental care worker, disposable glove use, history of jaundice, history of blood transfusion, clinical history of liver diseases, family history of liver disease and hepatitis B vaccination status.

Viral markers of hepatitis were measured by chemiluminescent enzyme immunoassay (CLEIA) including HBsAg, anti-HBs and anti-HBc and by solid phase RIA including anti-HCV. When the serum was HBsAg-positive, HBeAg (CLEIA), anti-HBe (CLEIA), HBV DNA level (PCR method) and HBV genotype (PCR method) were assayed; when the serum was anti-HBc-positive, the anti-HBc IgM and HBV DNA level were assayed; and when the serum was anti-HCV-positive, RT-PCR was carried out to determine quantitative HCV RNA and HCV genotype.

Results were mailed to each participant. Ethical guidelines for the research were observed closely in order to protect participant confidentiality.

\section{Results}

There were 141 (43 males and 98 females) participants. Table I shows 43 were in their 20 s, 35 in their 30 s, 36 in their 40s, 17 in their 50s, 7 in their 60s, 2 in their 70s and 1 in his 80 s. There were 42 dentists, 35 dental hygienists, 41 dental assistants, 8 dental mechanics and 15 clerks. Six subjects had a clinical history of liver disease that was unrelated to HBV or $\mathrm{HCV}$ infection.

As for hepatitis B vaccination, $68(48.2 \%)$ were and 63 $(44.7 \%)$ were not vaccinated. Dentists were the largest vaccinated group $(39.7 \%, 27 / 68)$ and dental assistants were the largest unvaccinated group $(34.9 \%, 22 / 63)$.

Regarding disposable glove use, only 9 people reported use of new gloves with every new patient. The highest number of people $(36 / 141)$ said that they changed gloves only when the

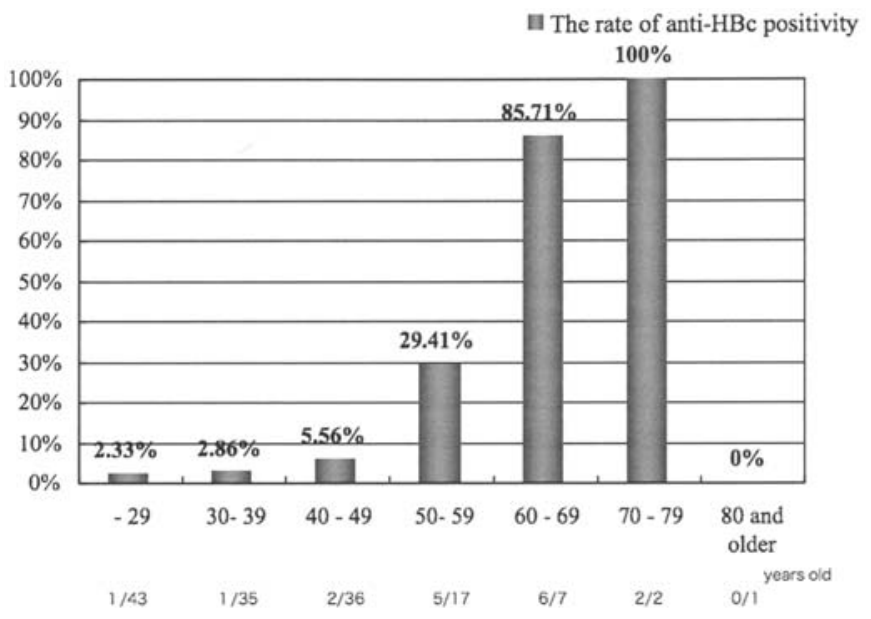

Figure 1. The rate of anti-HBc in 141 subjects classified according to age brackets. The rate of anti-HBc positivity increased with increased age.

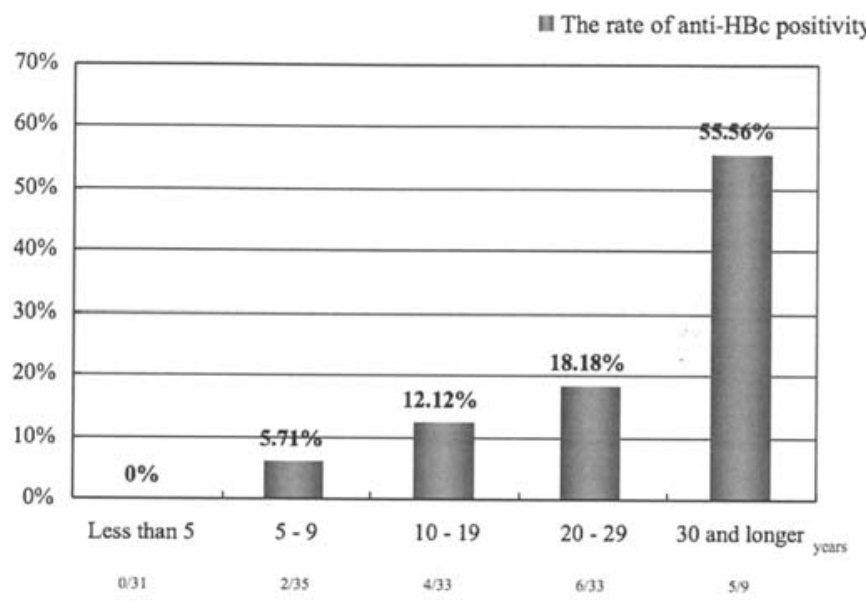

Figure 2. The rate of anti-HBc in 141 subjects classified according to years of experience in dental care. The rate of anti-HBc positivity increased with the number of years of dental care experience.

old pair of gloves were torn. Twenty-four workers did not wear gloves.

In hematological tests, no subjects were HBsAg-positive or anti-HCV-positive (Table II). However, 73 (51.8\%) subjects were anti-HBs-positive and $17(12.1 \%)$ were anti$\mathrm{HBc}-$ positive. The rates of anti-HBc positivity increased with age: $85.7 \%$ of subjects in their 60 s and $100 \%$ of subjects in their 70s (Fig. 1). The rate of anti-HBc positivity increased with the number of years of dental care experience (Fig. 2). As Table II shows, anti-HBs turned positive, indicating vaccine effectiveness, in $75 \%$ (51/68) of the vaccinated group and $27 \%(17 / 63)$ of the unvaccinated group. Fifteen of these 17 were anti-HBc-positive, indicating that these 15 were infected with $\mathrm{HBV}$ in the past.

Most $(52.9 \%)$ of the 17 anti-HBc-positive subjects were dentists (Table III). The largest proportion of the anti-HBcpositive subjects were in their $60 \mathrm{~s}(35.3 \%)$ and had 20 years of experience working in dentistry. Sixteen of the HBcpositive subjects $(94.1 \%)$ were anti-HBs-positive. However, no HBV DNA was detected in the blood. 


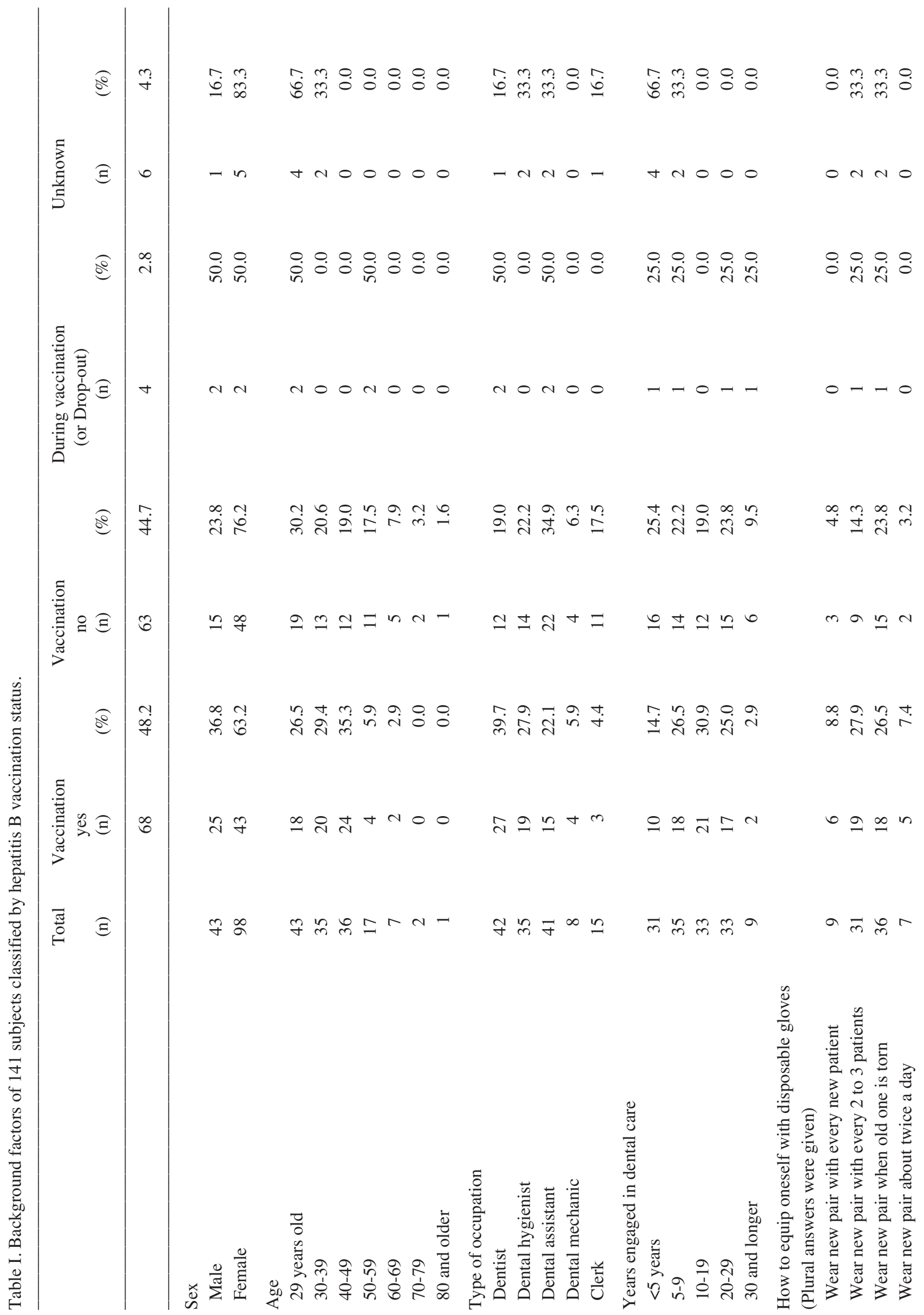




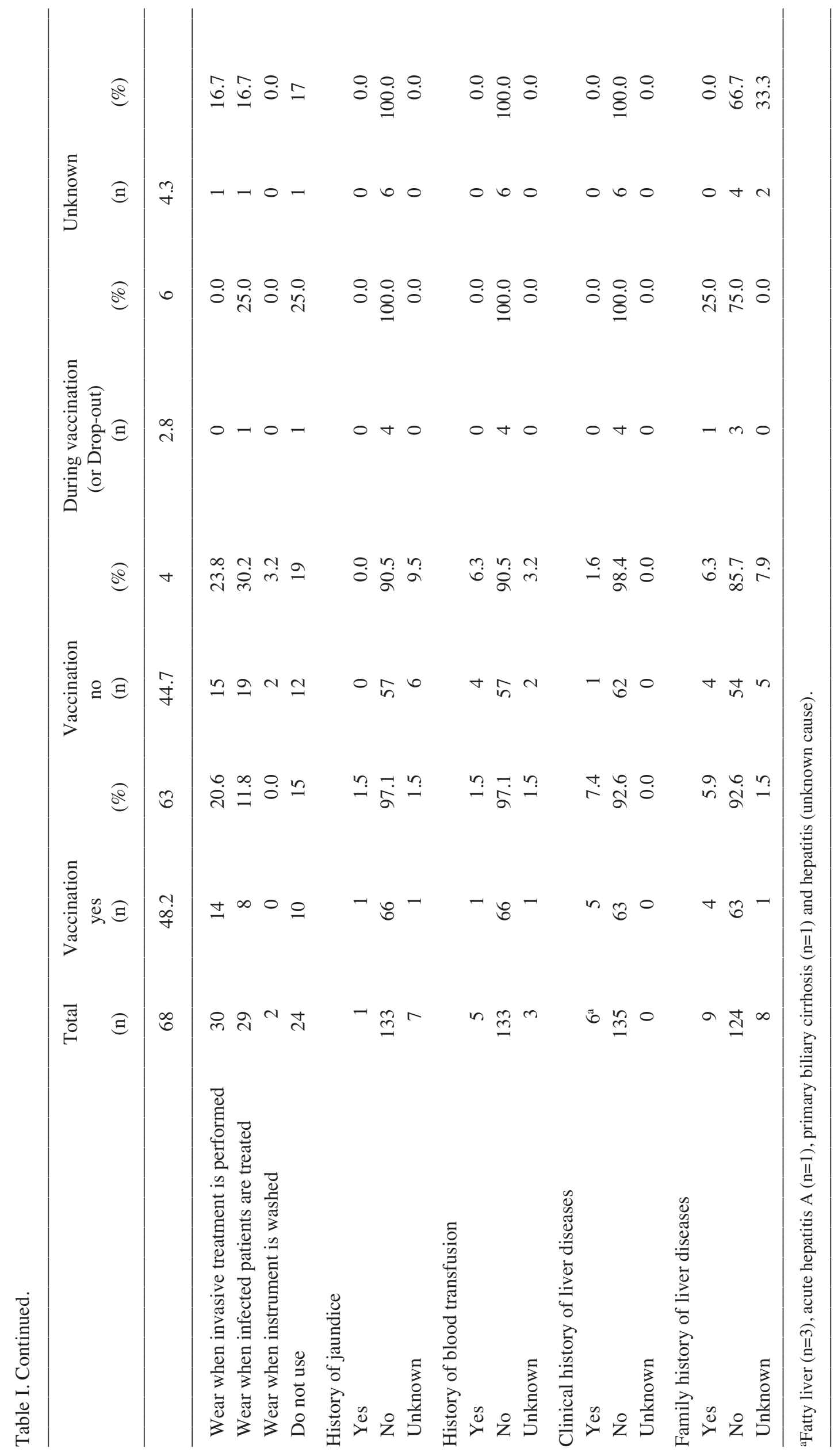




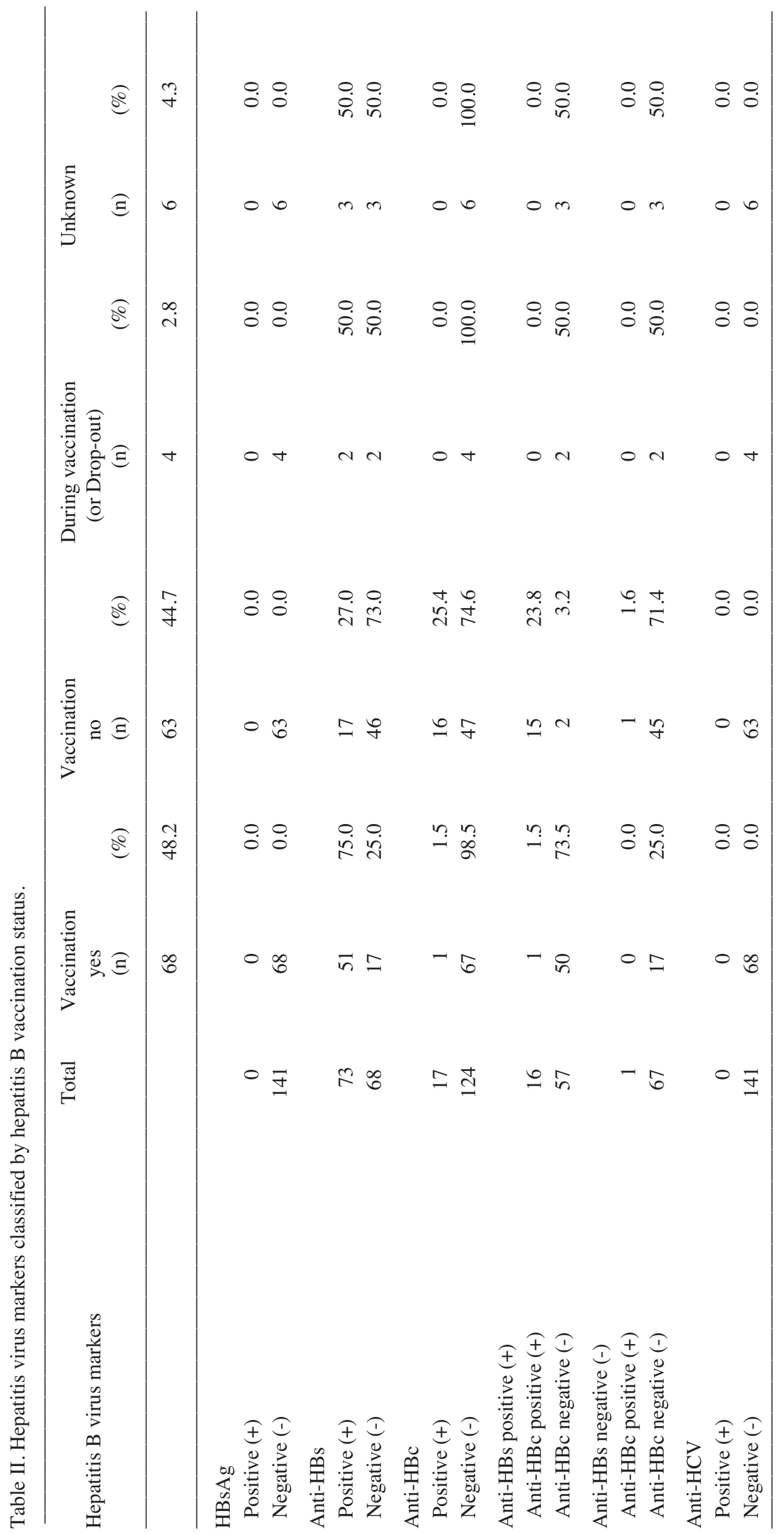


Table III. Breakdown of results classified by anti-HBc (+) and anti-HBc (-).

Subjects with anti-HBc (+) 17

(n)

(\%)

Hepatitis B vaccine

Vaccination yes

Vaccination no

During vaccination (or Drop-out)

Unknown

Sex

Male

Female

1

16

5.9

94.1

0

0.0

0.0

0

52.9

Age

29 years old

30-39

40-49

50-59

60-69

70-79

80 and older

Type of occupation

Dentist

Dental hygienist

Dental assistant

Dental mechanic

Clerk

Years engaged in dental care

$<5$ years

$5-9$

10-19

20-29

30 and longer

How to equip oneself with disposable gloves

(Plural answers were given)

Wear new pair with every new patient

Wear new pair with each 2 to 3 patients

Wear new pair when old one is torn

Wear new pair about twice a day

Wear when invasive treatment is performed

Wear when infected patients are treated

Wear when instrument is washed

Do not use

History of jaundice

Yes

No

Unknown

History of blood transfusion

Yes

No

Unknown
47.1

8

5.9

5.9

11.8

29.4

35.3

11.8

0.0

52.9

11.8

11.8

0.0

23.5

0.0

11.8

23.5

35.3

29.4

$34 \quad 27.4$

(n)

$(\%)$

Subjects with anti-HBc (-) 124

54.0

$47 \quad 37.9$

$4 \quad 3.2$

$6 \quad 4.8$

$90 \quad 72.6$

$\begin{array}{ll}42 & 33.9\end{array}$

$34 \quad 27.4$

$34 \quad 27.4$

$12 \quad 9.7$

$1 \quad 0.8$

$0 \quad 0.0$

$\begin{array}{ll}1 & 0.8\end{array}$

$33 \quad 26.6$

$33 \quad 26.6$

$39 \quad 31.5$

$8 \quad 6.5$

$11 \quad 8.9$

$31 \quad 25.0$

$33 \quad 26.6$

$29 \quad 23.4$

$27 \quad 21.8$

$\begin{array}{ll}4 & 3.2\end{array}$

\section{8}

.4

9
4
4
.7
.8
.0
.8

6

.5

\section{8}

5.0

6

21.8

.2


Table III. Continued.

Subjects with anti-HBc (+) 17

(n)

$(\%)$

No

Unknown

Subjects with anti-HBc (-) 124

(n)

$(\%)$

\begin{tabular}{|c|c|c|c|c|}
\hline \multicolumn{5}{|c|}{ Clinical history of liver diseases } \\
\hline Yes & 1 & 5.9 & 5 & 4.0 \\
\hline No & 16 & 94.1 & 119 & 96.0 \\
\hline Unknown & 0 & 0.0 & 0 & 0.0 \\
\hline \multicolumn{5}{|c|}{ Family history of liver diseases } \\
\hline Yes & 2 & 11.8 & 7 & 5.6 \\
\hline No & 15 & 88.2 & 109 & 87.9 \\
\hline Unknown & 0 & 0.0 & 8 & 6.5 \\
\hline \multicolumn{5}{|l|}{ HBsAg } \\
\hline Positive (+) & 0 & 0.0 & 0 & 0.0 \\
\hline Negative (-) & 17 & 100.0 & 124 & 100.0 \\
\hline \multicolumn{5}{|l|}{ Anti-HBs } \\
\hline Positive $(+)$ & 16 & 94.1 & 57 & 46.0 \\
\hline Negative (-) & 1 & 5.9 & 67 & 54.0 \\
\hline \multicolumn{5}{|l|}{ Anti-IgM-HBc } \\
\hline Positive (+) & 0 & 0.0 & - & - \\
\hline Negative (-) & 17 & 100.0 & - & - \\
\hline \multicolumn{5}{|c|}{ HBV DNA quantitative measurement } \\
\hline$\geq 2.6 \mathrm{log} / \mathrm{ml}$ & 0 & 0.0 & - & - \\
\hline$<2.6 \mathrm{log} / \mathrm{ml}$ & 17 & 100.0 & - & - \\
\hline
\end{tabular}

\section{Discussion}

HBV infection is transmitted mostly through blood and body fluid as a result of bites, administration of blood preparations, sexual activities and mother-infant transmission. The principal route of $\mathrm{HCV}$ infection is through blood. Medical care workers are always at risk of infection as they are exposed to contaminated fluids from needle sticks and infected blood droplets. Hepatitis B immune globulin (HBIG) has been used since 1981 and hepatitis B vaccination since 1985 (whole virus) and 1988 (recombinant) to prevent infection.

Dental care workers are often exposed to blood because of stomatorrhagia and the use of sharp instruments (11). Meticulous measures should be taken to protect against the spraying of saliva, which contains blood inside the examination room $(12,13)$. Our previous study reported that saliva from HCV carriers contained HCV RNA before and after scaling of dental calculus (14). HCV RNA was detected in exudates from gingival crevicular fluid and on materials used for making dental impressions, a work bench, an air turbine dental handpiece, holders, suction units, forceps, dental mirrors and cutting bar (15-17). HCV RNA was still detectable on the surface of dental instruments several days after the HCV carriers received treatment (18). Although their risk of infection is high, dental care workers are obligated to prevent cross infection (i.e., from dental care workers to patients and patients to patients). Although there are no documented cases of $\mathrm{HCV}$ transmission from dentists to patients, there is one case of the transmission of HBV by an oral surgeon (19).

Whether the disease is contracted depends on the levels of the virus in the blood, source of contamination, route of contact and blood volume transfused (20). The rate of acquiring HBV infection through HBV-contaminated needles is high [12\% (21) to $60 \%$ (22) in unvaccinated persons]. Wounds caused by needles that are contaminated with HBsAgand HBeAg-positive blood are associated with a 22-31\% risk of developing hepatitis B and a $37-62 \%$ probability of establishing HBV infection (23). Wounds caused by needles contaminated with HBsAg-positive and HBeAg-negative blood are associated with a 1-6\% risk of developing hepatitis $\mathrm{B}$ and a $23-37 \%$ probability of establishing HBV infection (21). However, infection can be prevented by HB vaccination and the administration of HBIG after these accidents occur.

Accidental prick with a needle contaminated with $\mathrm{HCV}$ positive blood caused HCV infection in $~ 1.4$ (24) to $10 \%$ (25) of cases. The probability of infection due to contaminated needle sticks is lower for HCV than HBV. However, the high risk of developing $\mathrm{HCC}$ through horizontal infection of $\mathrm{HCV}$ is a concern to often-exposed dentists. Feldman and Schiff found that hepatitis morbidity was $6.7 \%$ in dentists and $21 \%$ in oral surgeons in the State of Florida, USA (26). Although the risk of hepatitis among dentists is high, a long-term cohort study by Tanaka et al reported that liver cancer risk was no higher in Japanese dentists than in the general population (27). 
In the present investigation, 51 of the 68 recipients of the $\mathrm{HBV}$ vaccine were anti-HBs-positive, indicating that $75 \%$ of vaccinated subjects developed an antibody to HBV infection. Of the 63 unvaccinated subjects, $16(25.4 \%)$ were anti-HBcpositive and had no clinical history of HBV-related liver diseases, suggesting that they had been transiently and inapparently infected with HBV in the past. Only 1 (1.5\%) of the 68 vaccinated subjects was anti-HBc-positive, indicating the protection rate against $\mathrm{HBV}$ infection was higher in vaccinated than unvaccinated subjects and that vaccination was a useful protective measure.

The Japanese Red Cross introduced the Hemagglutination Inhibition Test (HI) in 1989 for the screening of anti-HBc (28) and the Nucleic Acid Amplification Test (NAT) in 1999 for the screening of $\mathrm{HBV}, \mathrm{HCV}$ and HIV in blood that was HBsAg-, anti-HBc-, anti-HCV- and anti-HIV-negative with ALT values <61 IU/1, dramatically increasing the safety of blood transfusion (29).

In Fukuoka and Kitakyushu Red Cross, 3,647 (1.1\%) of 323,799 blood donors screened between April 2003 and October 2004 were anti-HBc-positive. Of these 3,647, a total of 445 were $\mathrm{HBsAg}$-positive (30). In the remaining 3,202 anti-HBc-positive, HBsAg-negative donors, the rates of seroconversion to anti-HBc increased with age $(0.10,0.23$, $0.57,1.38,2.10$ and $2.29 \%$, respectively, in age groups 16-19, 20-29, 30-39, 40-49, 50-59 and 60-69).

Seroconversion to anti-HBc occurred at a significantly higher rate in dental care workers $(12.1 \%)$ than blood donors $(\mathrm{p}<0.05)$.

Anti-HBc is a marker of latent hepatitis B $(31,32)$. In previous years, it has been reported that HBV infection was transmitted through a liver transplanted from an anti-HBcpositive donor (32). HBV DNA has been detected in the serum of patients recovered from acute hepatitis B (33). Infection of latent $\mathrm{HBV}$ has been associated with the onset of HCV-related HCC $(34,35)$. Therefore, from the standpoint of health safety, the prevalence of latent $\mathrm{HBV}$ infection among dental care workers must be acknowledged.

Of the 63 unvaccinated subjects, only $4.8 \%$ changed gloves to a new pair for each new patient and $19 \%$ never wore gloves. Since dental care workers have a high risk of exposure to the hepatitis virus, a compulsory vaccination for the hepatitis B virus is desirable for all dental care workers. In Japan, hepatitis B vaccination is voluntary. However, from the standpoint of effectiveness and safety and to reduce infection risk, it is important to vaccinate these workers.

Regrettably, no hepatitis $\mathrm{C}$ vaccine or immunoglobulin has been developed to prevent $\mathrm{HCV}$ infection. Although no persistent carriers of $\mathrm{HBV}$ and $\mathrm{HCV}$ were detected in the present investigation, the rate of infection is higher in the western portion of Japan, especially in the Saga and Fukuoka prefectures, than eastern Japan. Therefore, further precautions must be taken.

\section{Acknowledgements}

This study was supported by a Grant-in-Aid for Scientific Research (C) (No. 18592213) from the Japanese Ministry of Education, Culture, Sports, Science and Technology of Japan. We thank Dr Masahiro Tsuji, Dr Masakatsu Shimada and Dr Masahide Tsuji for support.

\section{References}

1. Higuchi M, Tanaka E and Kiyosawa K: Epidemiology and clinical aspects on hepatitis C. Jpn J Infect Dis 55: 69-77, 2002.

2. Batista SM, Andreasi MS, Borges AM, et al: Seropositivity for hepatitis B virus, vaccination coverage, and vaccine response in dentists from Campo Grande, Mato Grosso do Sul, Brazil. Mem Inst Oswaldo Cruz 101: 263-267, 2006.

3. Cleveland JL, Siew C, Lockwood SA, Gruninger SE, Gooch BF and Shapiro CN: Hepatitis B vaccination and infection among U.S. dentists, 1983-1992. J Am Dent Assoc 127: 1385-1390, 1996.

4. Ammon A, Reichart PA, Pauli G and Petersen LR: Hepatitis B and $\mathrm{C}$ among Berlin dental personnel: incidence, risk factors, and effectiveness of barrier prevention measures. Epidemiol Infect 125: 407-413, 2000.

5. Reingold AL, Kane MA and Hightower AW: Failure of gloves and other protective devices to prevent transmission of hepatitis B virus to oral surgeons. JAMA 259: 2558-2560, 1988.

6. Thomas DL, Gruninger SE, Siew C, Joy ED and Quinn TC: Occupational risk of hepatitis $\mathrm{C}$ infections among general dentists and oral surgeons in North America. Am J Med 100: 41-45, 1996.

7. Shinozaki F, Hayatsu Y, Iwai M, et al: Investigation of the hepatitis B virus infection among dentist in Hokkaido area (in Japanese). Jpn J Oral Maxillofac Surg 26: 361-365, 1980.

8. Shinozaki F, Hayatsu Y, Iwai M, Kumagai S and Kohama G: A seroepidemiologic survey of hepatitis B virus infection among the dentist in Japan (in Japanese). Jpn J Oral Maxillofac Surg 29: 1865-1871, 1983.

9. Shinozaki F, Hayatsu Y, Fukuda T, Suetsugu M and Mizugaki Y: A seroepidemiologic survey of hepatitis $C$ virus infection among the dentist in Japan (in Japanese). J Jpn Stomatol Soc 44: 438-441, 1995.

10. Klein RS, Freeman K, Taylor PE and Stevens CE: Occupational risk for hepatitis $\mathrm{C}$ virus infection among New York City dentists. Lancet 338: 1539-1542, 1991.

11. Siew C, Gruninger SE, Miaw CL and Neidle EA: Percutaneous injuries in practicing dentists: a prospective study using a 20-day diary. J Am Dent Assoc 126: 1227-1234, 1995.

12. Davison F, Alexander GJ, Trowbridge R, Fagan EA and Williams R: Detection of hepatitis B virus DNA in spermatozoa, urine, saliva and leucocytes, of chronic HBsAg carriers. A lack of relationship with serum markers of replication. J Hepatol 4: 37-44, 1987.

13. Komiyama K, Moro I, Mastuda Y, et al: $\mathrm{HCV}$ in saliva of chronic hepatitis patients having dental treatment. Lancet 338: 572-573, 1991.

14. Nagao Y, Seki N, Tamatsukuri S and Sata M: Detection of hepatitis $\mathrm{C}$ virus in saliva before and after scaling of dental calculus. Kansenshogaku Zasshi 74: 961-965, 2000.

15. Furuya $\mathrm{H}$ : A fact-finding on dental care of suspected hepatitis $\mathrm{C}$ patients-Hepatitis and Other Diseases Conquest Emergency Measures Study Project (hepatitis division). Study on reduction of infection risk of hepatitis $\mathrm{C}$ in dental care. Summary of assignment reports (in Japanese). Health and Labour Sciences Research Grants, Ministry of Health, Labour, and Welfare, Japan, pp6-11, 2002.

16. Piazza M, Borgia G, Picciotto L, Nappa S, Cicciarello S and Orlando R: Detection of hepatitis C virus-RNA by polymerase chain reaction in dental surgeries. J Med Virol 45: 40-42, 1995.

17. Maticic M, Poljak M, Kramar B, et al: Detection of hepatitis C virus RNA from gingival crevicular fluid and its relation to virus presence in saliva. J Periodontol 72: 11-16, 2001.

18. Fong TL, Charboneau F, Valinluck B and Govindarajan S: The stability of serum hepatitis C viral RNA in various handling and storage conditions. Arch Pathol Lab Med 117: 150-151, 1993.

19. Rimland D, Parkin WE, Miller GB Jr and Schrack WD: Hepatitis B outbreak traced to an oral surgeon. Hepatitis B outbreak traced to an oral surgeon. N Engl J Med 296: 953-958, 1977.

20. Chiarello LA and Bartley JB: Prevention of blood exposure in health care personnel. Semin Infect Control 1: 30-43, 2001.

21. Werner BG and Grady GF: Accidental hepatitis-B-surfaceantigen-positive inoculations. Use of e antigen to estimate infectivity. Ann Intern Med 97: 367-369, 1982. 
22. U.S. National Heart and Lung Institute Collaborative Study Group and Phoenix Laboratories Division, Bureau of Epidemiology, Center for Disease Control: Relation of e antigen to infectivity of $\mathrm{HBsAg}$-positive inoculations among medical personnel. Lancet 1: 492-494, 1976.

23. CDC. Updated U.S. Public Health Service Guidelines for the Management of Occupational Exposures to HBV, HCV, and HIV and Recommendations for Postexposure Prophylaxis. 50 (RR11): 1-42, 2001.

24. Sodeyama T, Kiyosawa K, Urushihara A, et al: Detection of hepatitis $\mathrm{C}$ virus markers and hepatitis $\mathrm{C}$ virus genomic-RNA after needlestick accidents. Arch Intern Med 153: 1565-1572, 1993.

25. Mitsui T, Iwano K, Masuko K, et al: Hepatitis C virus infection in medical personnel after needlestick accident. Hepatology 16: 1109-1114, 1992

26. Feldman RE and Schiff ER: Hepatitis in dental professionals. JAMA 232: 1228-1230, 1975.

27. Tanaka H, Nishio N, Tokunaga R and Tsukuma H: Liver cancer risk in Japanese male dentists: a long-term retrospective cohort study. J Occup Health 46: 398-402, 2004.

28. Iizuka H, Ohmura K, Ishijima A, et al: Correlation between anti-HBc titers and HBV DNA in blood units without detectable HBsAg. Vox Sang 63: 107-111, 1992.

29. Japanese Red Cross NAT Screening Research Group: Nationwide nucleic acid amplification testing of hepatitis B virus, hepatitis $\mathrm{C}$ virus and human immunodeficiency virus type 1 for blood transfusion and follow-up study of nucleic acid amplification positive donors. Jpn J Infect Dis 53: 116-123, 2000.
30. Yamasaki H, Manabe K, Matsumoto K, et al: The effect of notification of antibody to hepatitis $\mathrm{B}$ core antigen to voluntary donors (in Japanese). Ketsuekijigyo 28: 413-419, 2005.

31. Joller-Jemelka HI, Wicki AN and Grob PJ: Detection of HBs antigen in 'anti-HBc alone' positive sera. J Hepatol 21: 269-272, 1994.

32. Dickson RC, Everhart JE, Lake JR, et al: Transmission of hepatitis $\mathrm{B}$ by transplantation of livers from donors positive for antibody to hepatitis B core antigen. The National Institute of Diabetes and Digestive and Kidney Diseases Liver Transplantation Database. Gastroenterology 113: 1668-1674, 1997.

33. Michalak TI, Pasquinelli C, Guilhot S and Chisari FV: Hepatitis B virus persistence after recovery from acute viral hepatitis. J Clin Invest 93: 230-239, 1994.

34. Marusawa H, Osaki Y, Kimura T, et al: High prevalence of anti-hepatitis B virus serological markers in patients with hepatitis C virus related chronic liver disease in Japan. Gut 45: 284-288, 1999.

35. Tanaka K, Nagao Y, Ide T, Kumashiro R and Sata M: Antibody to hepatitis B core antigen is associated with the development of hepatocellular carcinoma in hepatitis $C$ virus-infected persons: a 12-year prospective study. Int J Mol Med 17: 827-832, 2006. 